\title{
World Englishes: uma unidade didática desenvolvida para jovens em situação de vulnerabilidade
}

\section{Resumo}

Este artigo descreve uma unidade didática (UD) de inglês como língua adicional para jovens de classe baixa e média-baixa, moradores de uma comunidade em situação de vulnerabilidade, localizada em Porto Alegre. A UD é um recorte de um projeto de dissertação cujo objetivo é desenvolver um curso voltado para as necessidades e os interesses dos membros da comunidade. A proposta é baseada em estudos sobre aprendizagem colaborativa, educação popular, variação linguística, gêneros do discurso e aprendizagem baseada em tarefas. O objetivo principal é reconhecer as variações possíveis entre falantes da mesma língua, já que se considera fundamental no ensino de línguas a abordagem sobre as diversas manifestações do idioma que diferem do padrão, assim como a compreensão dos aspectos culturais envolvidos nos fenômenos linguísticos. Considerando a realidade dos alunos, propõe-se a discussão sobre as variações na língua inglesa partindo-se do mesmo fenômeno na língua portuguesa.

Palavras-chave: Aprendizagem colaborativa. Língua inglesa. Educação popular.

\section{Introdução e contextualização}

Este artigo apresenta uma unidade didática (UD) para o ensino de inglês como língua adicional ${ }^{1}$ elaborada para jovens de classe baixa e média-baixa, moradores de uma comunidade em si-

\footnotetext{
Graduada em Pedagogia pela Universidade Federal do Rio Grande do Sul (UFGRS). Tem experiência na área de Educação. Atuou como professora nos anos inicias e atualmente é professora de Língua Inglesa. Possui formação em Círculos de Construção de Paz pelo programa Escola + Paz, por isso pesquisou sobre os efeitos da Justiça Restaurativa na educação e na sala de aula. Atualmente pesquisa e se interessa sobre Linguística Aplicada, especificamente na influência do planejamento e da prática docente na relação dos discentes com a língua adicional. E-mail: fernandarbkl@gmail.com

"* É professora associada da Universidade Federal do Rio Grande do Sul (UFRGS). Atua na graduação em Letras-Inglês e no Programa de Pós-Graduação em Letras, na linha de pesquisa em Linguística Aplicada. Possui Mestrado e Doutorado em Letras pela Pontifícia Universidade Católica do Rio Grande do Sul. Realizou estágio de pós-doutorado na Universidad de Málaga e na City University of New York. Seus principais interesses de pesquisa são nas áreas de formação de professores, letramento, produção de material didático para o ensino de línguas adicionais, políticas linguísticas, internacionalização e educação bilíngue. Atualmente é coordenadora do projeto interdisciplinar Letras português-inglês e Ciências da Natureza do Programa Residência Pedagógica na UFRGS e editora-chefe da RevistaBem Legal. E-mail: anamaria.welp@ufrgs.br
}

Data de submissão: set. 2020 - Data de aceite: nov. 2020

http://dx.doi.org/10.5335/rdes.v16i3.11397 
tuação de vulnerabilidade, localizada na zona centro-sul de Porto Alegre. A UD é um recorte de um projeto de pesquisa de mestrado cujo objetivo é desenvolver um curso e uma progressão curricular voltados para as necessidades e interesses dos membros da comunidade, composta por aproximadamente 550 moradores, distribuídos em 110 residências, dos quais 20 demonstraram interesse no curso. As atividades serão realizadas na sede da organização não governamental, a qual está localizada na comunidade em questão. A UD que integrará o currículo, e que foi desenvolvida especialmente para esse público, tem como objetivo abordar a variação linguística e pode ser adaptada e utilizada por professores de inglês, principalmente em escolas da rede pública e iniciativas não governamentais.

A questão de como tornar o ensino de línguas adicionais para o público em questão mais atrativo e significativo para os aprendizes se torna central, assim como o desenvolvimento de tarefas adequadas que promovam a aprendizagem da língua através da reflexão crítica (GADOTTI, 2012) sobre vários temas. Nesse sentido, o curso está sendo desenvolvido inicialmente de acordo com documentos oficiais como os Referenciais Curriculares (RCs) do Rio Grande do Sul e a Base Nacional Comum Curricular (BNCC). Além disso, estudos sobre aprendizagem colaborativa (SCHLATTER; GARCEZ, 2012), educação popular (GADOTTI, 2012) pesquisas variacionistas na escola (MANGABEIRA, 2012), gêneros do discurso (BAKHTIN, 2010) e aprendizagem baseada em tarefas (VAN DEN BRANDEN, 2016) contribuíram para a construção da proposta pedagógica aqui descrita.

Tendo em vista que as aulas acontecerão duas vezes por semana, com duração de uma hora cada, a UD foi dividida em seis aulas, podendo ser alterada à medida que os encontros acontecem, tendo em vista que o principal objetivo de aprendizagem previsto é reconhecer as variações presentes na fala de falantes da língua inglesa. Partindo dos conhecimentos prévios dos alunos sobre variação linguística na língua portuguesa, a exploração é feita através da investigação de diferentes variantes e formas de se expressar em inglês. É importante ressaltar que a UD apresentada aqui será abordada no início da progressão curricular, com o intuito de provocar os alunos em relação às possibilidades de expressão e variação existentes nas línguas.

$\mathrm{O}$ artigo está organizado em quatro partes. Após a introdução, são abordados os referenciais teóricos que embasaram o desenvolvimento da proposta. Na seção seguinte, é descrita a maneira como as tarefas estão organizadas temporalmente ao longo dos encontros e, após, na mesma seção, são apresentadas as tarefas que serão utilizadas com os alunos. Por fim, na última seção são apresentadas as considerações finais. 


\section{Implicações da variação linguística no ensino/aprendizagem colaborativo}

De acordo com a perspectiva adotada aqui, considera-se fundamental no ensino de línguas a abordagem sobre as diversas manifestações do idioma que diferem do padrão, assim como a compreensão dos aspectos culturais que envolvem os usos da língua. Dessa forma, partindo da realidade dos alunos e do público da comunidade, propõe-se a discussão sobre as variações na língua portuguesa para que então seja iniciado o estudo sobre o mesmo fenômeno na língua inglesa. Nessa perspectiva, como afirma Welp (2011), devemos atentar ao fato de que o aluno chega à escola, ou neste caso, ao curso de língua, com o seu repertório linguístico e cabe ao professor criar condições para que tal repertório seja ampliado. Da mesma forma, para Gadotti (2012), a Educação Popular é um movimento de natureza social, popular, cidadã, cívica e comunitária, que está marcado pela diversidade, em vista disto os repertórios dos alunos devem ser compreendidos, respeitados e valorizados. Assim, o conjunto de tarefas interligadas que compõem a unidade didática proporciona a exploração da língua de maneira interdisciplinar reconhecendo e valorizando aquilo que os alunos já sabem, suas vidas e suas possibilidades de ação na sala de aula. Para além, busca proporcionar oportunidades para que eles explorem a língua inglesa e seus usos através da exposição a diferentes comunidades de falantes, mediante a realização de tarefas contextualizadas e significativas. Assim, acredita-se que a exploração de textos autênticos, através de tarefas, promove o uso da língua para se fazer coisas no mundo (CLARK, 2000), mas também possibilita a interação através de objetivos não linguísticos (VAN DEN BRANDEN, 2016).

Nesse contexto, as tarefas presentes na proposta didática em questão, e ao longo da progressão curricular proposta na dissertação, são desenvolvidas a partir de diferentes suportes e gêneros do discurso que possibilitam inesgotáveis fontes de exploração e interpretação dos sujeitos sobre a língua em diferentes tempos e espaços (BAKHTIN, 2010). Sobre isso, considera-se que para formar cidadãos:

[...] devemos ensiná-los a valorizar a flexibilidade estrutural de uma língua e a riqueza expressiva à disposição de seus falantes e a ver essa língua como um conjunto múltiplo e diverso de variedades geográficas, sociais, estilísticas, de registro e de gêneros textuais e discursivos (WELP, 2011, p. 5).

Ainda, sobre esse tema, o uso de gêneros do discurso se justifica quando focamos na promoção do uso da linguagem para a realização de ações significativas para os estudantes (SCHLATTER; GARCEZ, 2012). 
Partindo do conceito de aprendizagem colaborativa, compreende-se que a sala de aula constitui um espaço onde todos ensinam, todos aprendem (SCHLATTER; GARCEZ, 2012) e, por isso, considera-se imprescindível a adoção de práticas que promovam a interação entre os aprendizes e o professor. Dessa forma, assim como Schlatter e Garcez (2012), entendemos que a aprendizagem, vista como uma atividade colaborativa, tem um papel central quando os alunos participam das práticas da comunidade realizando ações conjuntas em sala de aula e utilizando a língua para realizá-las. Nesse contexto, cabe ao professor propor a seus alunos oportunidades para que adquiram confiança através da participação em novas e antigas práticas sociais (SCHLATTER; GARCEZ, 2012). Além disso, é fundamental considerar que, ao perceber os usos que já circulam em comunidades de outros falantes, os aprendizes têm uma melhor compreensão tanto das línguas que já conhecem quanto daquela que estão aprendendo.

Considerando a atuação do professor, entende-se que ele assume "o papel de um interlocutor mais experiente que pode orientar e auxiliar o educando a participar" das práticas sociais perpassadas pela língua (SCHLATTER; GARCEZ, 2012, p. 170). Com esse objetivo, considera-se que o processo de ensino e aprendizagem deve compreender dinâmicas que promovam a construção do conhecimento através do diálogo e da colaboração entre todos os envolvidos.

Nesse sentido, entende-se que, ao desempenhar as tarefas propostas, cada indivíduo realiza ações individuais e conjuntas e, consequentemente, aprende com os seus pares e com o professor. As tarefas, por sua vez, funcionam como mediadoras desse processo, já que promovem a cooperação e a ajuda mútua entre os integrantes da turma (SCHLATTER; GARCEZ, 2012). Além disso, os textos explorados através das tarefas, em português e em inglês, promovem a reflexão dos alunos sobre as línguas, mas também sobre aspectos relevantes acerca de seu país e de suas realidades, já que, principalmente na educação popular, faz-se necessário a conscientização de que somos "agentes de transformação do outro e da realidade" (MEDEIROS; FONTOURA, 2017, p. 89), dessa forma somos todos, professores e aluno, seres inacabados e estamos sempre aprendendo com o outro.

Realizar tarefas que envolvam a língua adicional é participar das atividades em sala de aula como membro desse grupo e como coautor responsável pelo que está sendo construído na relação com os outros. Assim, conclui-se que a promoção da aprendizagem de uma língua adicional deve se orientar por amplos parâmetros de formação de cidadãos capazes de participar de forma crítica no mundo e de transitar na sociedade 
contemporânea preparados para lidar com a diversidade e a interculturalidade (SCHLATTER; GARCEZ, 2012).

Por fim, com o intuito de abarcar os eixos organizadores da BNCC para língua inglesa (oralidade, leitura, escrita, conhecimentos linguísticos e dimensão intercultural), as tarefas compostas por textos autênticos são desenvolvidas de maneira dinâmica, em que os estudantes têm a oportunidade de argumentar, ler, escrever e desenvolver o conhecimento linguístico através de conversas sobre os aspectos culturais envolvidos pela língua e seus usos. O documento da BNCC também reconhece o status do inglês como língua franca, assim como o entendimento do inglês como língua global (CRYSTAL, 2009) e adicional, e envolve a perspectiva de língua na qual

[...] são acolhidos e legitimados os usos que dela fazem falantes espalhados no mundo inteiro, com diferentes repertórios linguísticos e culturais, o que possibilita, por exemplo, questionar a visão de que o único inglês "correto" - e a ser ensinado - é aquele falado por estadunidenses ou britânicos (BRASIL, 2018, p. 241).

Conforme se vê no Quadro 1:

Quadro 1 - Progressão das tarefas

\begin{tabular}{|c|c|c|c|}
\hline Tarefa & Objetivo da tarefa & Tipo de tarefa & Gênero discursivo \\
\hline $\begin{array}{l}\text { I: Introduction to the } \\
\text { topic } \\
\text { Aula } 1\end{array}$ & $\begin{array}{l}\text { Conversar sobre variações na língua } \\
\text { portuguesa pelo Brasil a partir de co- } \\
\text { nhecimentos prévios }\end{array}$ & $\begin{array}{l}\text { Discussão de perguntas em } \\
\text { grupo: ativação de conheci- } \\
\text { mentos prévios }\end{array}$ & Imagem \\
\hline $\begin{array}{l}\text { II: World Portugueses } \\
\text { Aula } 1\end{array}$ & $\begin{array}{l}\text { Investigar diferentes variações do } \\
\text { português pelo mundo }\end{array}$ & $\begin{array}{l}\text { Encontrar informações em } \\
\text { um vídeo e leitura de texto }\end{array}$ & Vídeo \\
\hline $\begin{array}{l}\text { III: World Englishes } \\
\text { Aula } 2\end{array}$ & $\begin{array}{l}\text { Reconhecer a diversidade de varia- } \\
\text { ções da língua inglesa pelo mundo }\end{array}$ & $\begin{array}{l}\text { Fazer uma lista, responder } \\
\text { perguntas e realizar ativida- } \\
\text { de online }\end{array}$ & Mapa interativo \\
\hline $\begin{array}{l}\text { IV: English as a Glo- } \\
\text { bal Language } \\
\text { Aula } 3\end{array}$ & $\begin{array}{l}\text { Reconhecer os aspectos históricos e } \\
\text { culturais que influenciam no entendi- } \\
\text { mento de inglês como língua global }\end{array}$ & $\begin{array}{l}\text { Leitura e interpretação de } \\
\text { texto }\end{array}$ & Trecho de um livro \\
\hline $\begin{array}{l}\text { V: Words and culture } \\
\text { Aula } 4\end{array}$ & $\begin{array}{l}\text { Relacionar as variações da língua de } \\
\text { acordo com o tempo e o espaço }\end{array}$ & $\begin{array}{l}\text { Interpretação de charge e ex- } \\
\text { ploração de vocabulário atra- } \\
\text { vés de reflexão linguística }\end{array}$ & Charge \\
\hline $\begin{array}{l}\text { VI: Same words diffe- } \\
\text { rent pronunciation } \\
\text { Aula } 5\end{array}$ & $\begin{array}{l}\text { Compreender que a pronúncia das } \\
\text { palavras varia de acordo com quem } \\
\text { fala }\end{array}$ & Leitura e gravação de voz & Citação \\
\hline $\begin{array}{l}\text { VII: Brazilian spea- } \\
\text { king Portuguese } \\
\text { Aula } 6\end{array}$ & $\begin{array}{l}\text { Analisar os aspectos variáveis na } \\
\text { fala de um brasileiro falante de inglês } \\
\text { como língua adicional }\end{array}$ & Observação de vídeo & Vídeo \\
\hline $\begin{array}{l}\text { VIII: Final task } \\
\text { Aula } 7\end{array}$ & $\begin{array}{l}\text { Produzir um vídeo em grupo expres- } \\
\text { sando uma frase sobre variação lin- } \\
\text { guística }\end{array}$ & $\begin{array}{l}\text { Produção de conteúdo au- } \\
\text { diovisual em grupo }\end{array}$ & \\
\hline
\end{tabular}

Fonte: elaboração dos autores. 
Quadro 2 - Tarefa I: Introducing the topic - variations of Portuguese

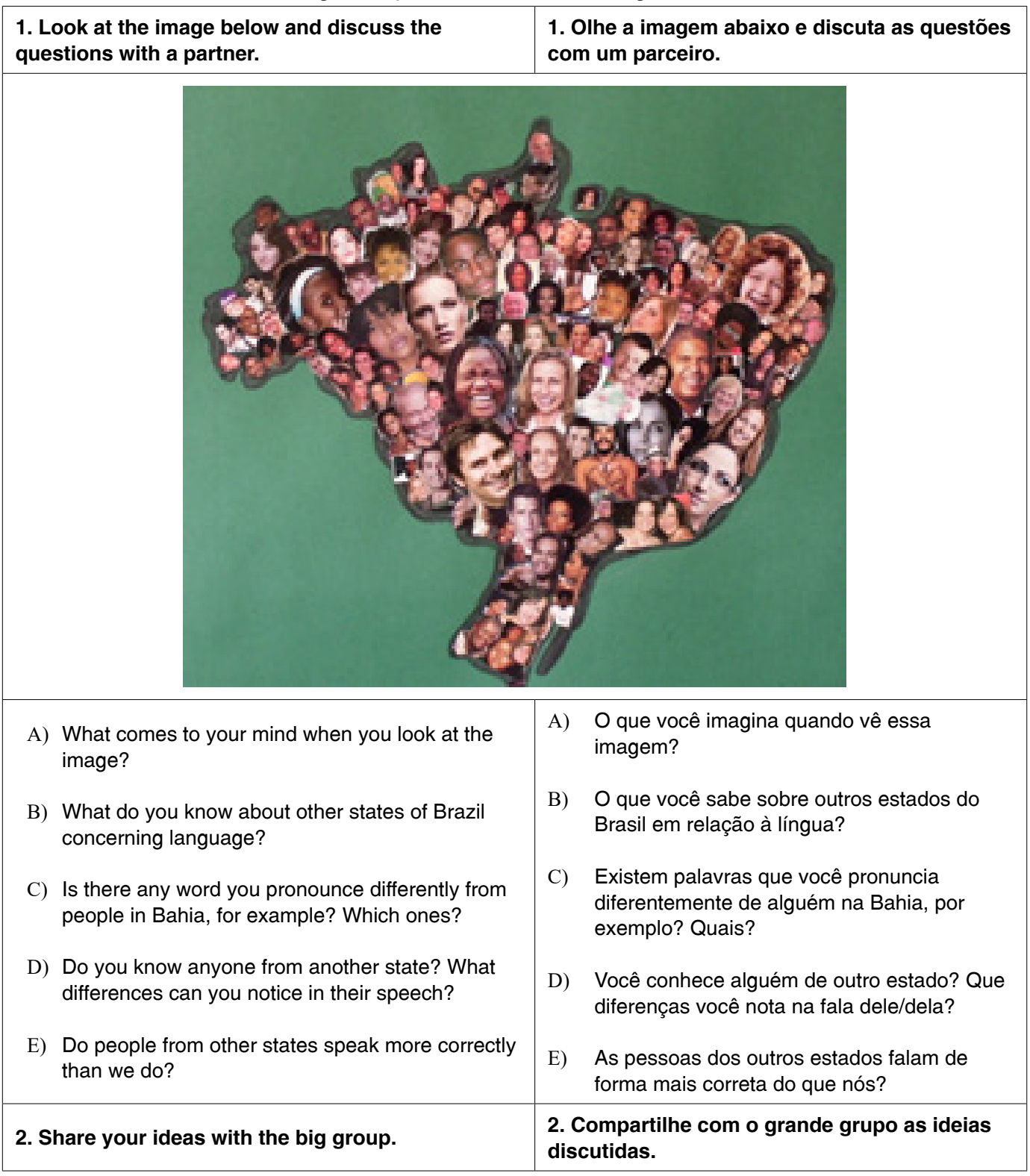

Fonte: elaboração dos autores. 
Quadro 3 - Tarefa II: World Portugueses

1. You're going to watch a video about "different Portugueses". Before you do it, answer the questions below.

a) In how many countries is Portuguese spoken?

b) Is there a more correct Portuguese? Explain your answer.

2. Watch the video and check your answers. Have you changed your mind?

https://www.youtube.com/watch?v=EA429o8uFxk
1. Você vai assistir a um vídeo sobre os "diferentes portugueses". Antes disso, responda as perguntas abaixo.

a) Em quantos países se fala português?

b) Existe um português mais correto? Explique sua resposta.

2. Assista ao vídeo e confira suas respostas. Você mudou de ideia?

https://www.youtube.com/watch?v=EA42908uFxk

3. Read the extract below and answer the questions again/ Leia o excerto abaixo e responda às perguntas novamente.

\section{Where Is Portuguese Spoken?}

Portuguese is an official language in ten countries, including Brazil, Mozambique, Angola, Portugal, Guinea-Bissau, East Timor, Equatorial Guinea, Macau, Cape Verde, and São Tomé and Príncipe.

During the Portuguese discoveries of the 15th and 16th centuries, the Portuguese language was brought to many regions in Africa, Asia and the Americas. Local officials and Europeans of all nationalities used Portuguese as a lingua franca (a common language) to facilitate communication.

Adapted from: https://www.babbel.com/en/magazine/how-many-people-speak-portuguese-and-where-is-itspoken

4. Identify in the image below where the countries are and write their names. If necessary, check a map. / Identifique e escreva os nomes dos países na imagem abaixo. Se necessário, consulte um mapa.
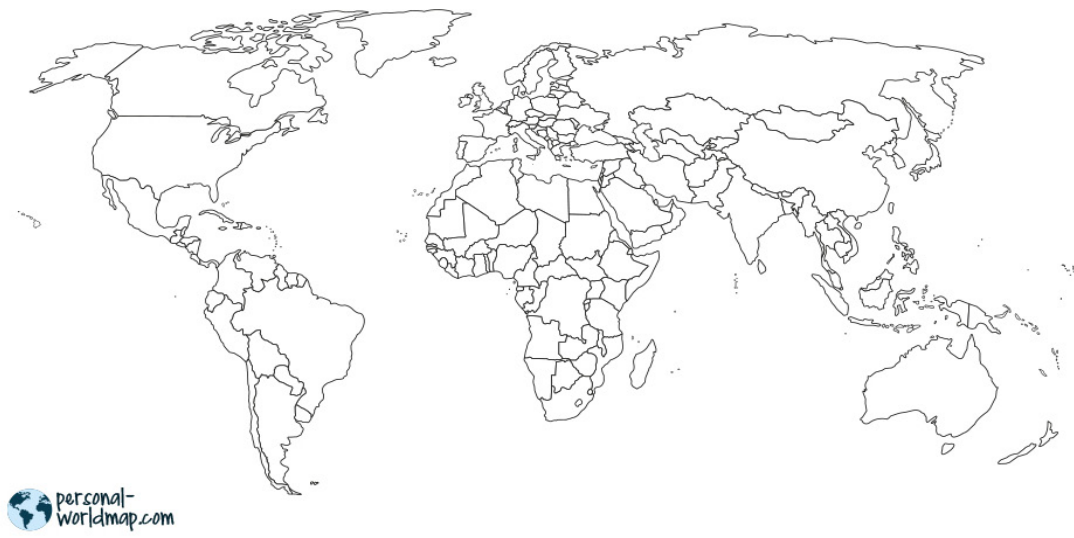

Source: http://my-travelmap.com/designs

Fonte: elaboração dos autores. 
Quadro 4 - Tarefa III: World Englishes

1. Make a list of the countries where English is the most spoken language.

2. Check your list with a partner and answer the questions below:

a) In your opinion, do all these countries have English as a home language?

b) Do you think people speak English in the same way as they speak their home languages?

c) What differences might exist among these Englishes?

\section{Explore different pronunciations of English} using the website:
1. Faça uma lista dos países em que o inglês é a língua mais falada.

2. Confira sua lista com um colega e respondam as perguntas abaixo:

a) Na sua opinião, o inglês é a língua falada nos lares de todos esses países?

b) Vocês acham que as pessoas falam inglês do mesmo jeito que eles falam sua língua primeira língua?

c) Que diferenças podem existir entre esses ingleses?

\section{Explore diferentes pronúncias do Inglês} utilizando o site:

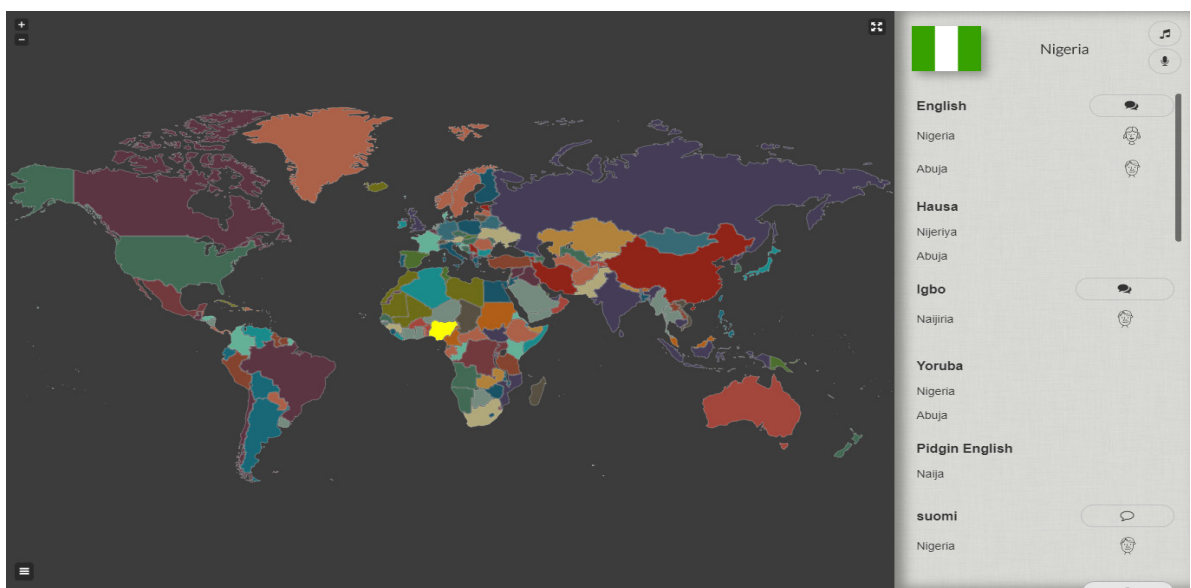

https://localingual.com/

Fonte: elaboração dos autores. 
Quadro 5 - Tarefa IV: English as a Global Language

1. Look at the image and answer the question:

1. Olhe para a imagem e responda a pergunta:

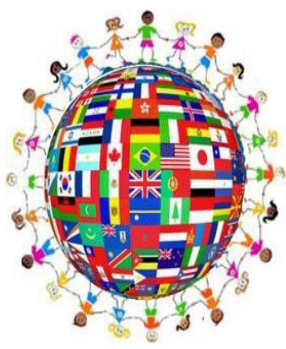

What does the global language status mean to you?

Source: http://www.bookwormsandowls.com/

2. In the book "English as a Global Language", the author David Crystal brings up some questions about the status of "English as global language" (p. 2). Read and think of an answer to each one:

2. No livro English as a Global Language o autor David Crystal propõe perguntas sobre o status de inglês como língua global (p.2). Leia as perguntas e pense em uma possível resposta para cada uma:

Why a global language?

'English is the global language.'

a) Does everyone in the world speak English?

b) Does every country in the world recognize English as an official language?

c) What does it mean to say that a language is a global language?

d) Why is English the language that's usually mentioned as the global language?

e) Once a language becomes a global language, is it forever? Do you think there were other global languages in the history of mankind? Can you name one?

3. Now read the extract adapted from the book "English as a Global Language" and discuss with the group possible answers for the first question.

3. Agora leia o trecho adaptado do livro English as a Global Language e discuta com o grupo possíveis respostas para a primeira pergunta da atividade.

Why a language becomes a global language has little to do with the number of people who speak it. It has much more to do with who those speakers are. [...] There is a link between language dominance and economic, technological, and cultural power, too, and this is part of the history of English. A strong power-base is fundamental for a language to progress as an international medium of communication. Language has no independent existence, apart from the people who speak it. Language exists only in the brains and mouths and ears and hands and eyes of its users.

Source: English as Global Language by David Crystal (2009)

4. Discuss the ideas with the group.

4. Discuta as ideias com o grupo.

Fonte: elaboração dos autores. 


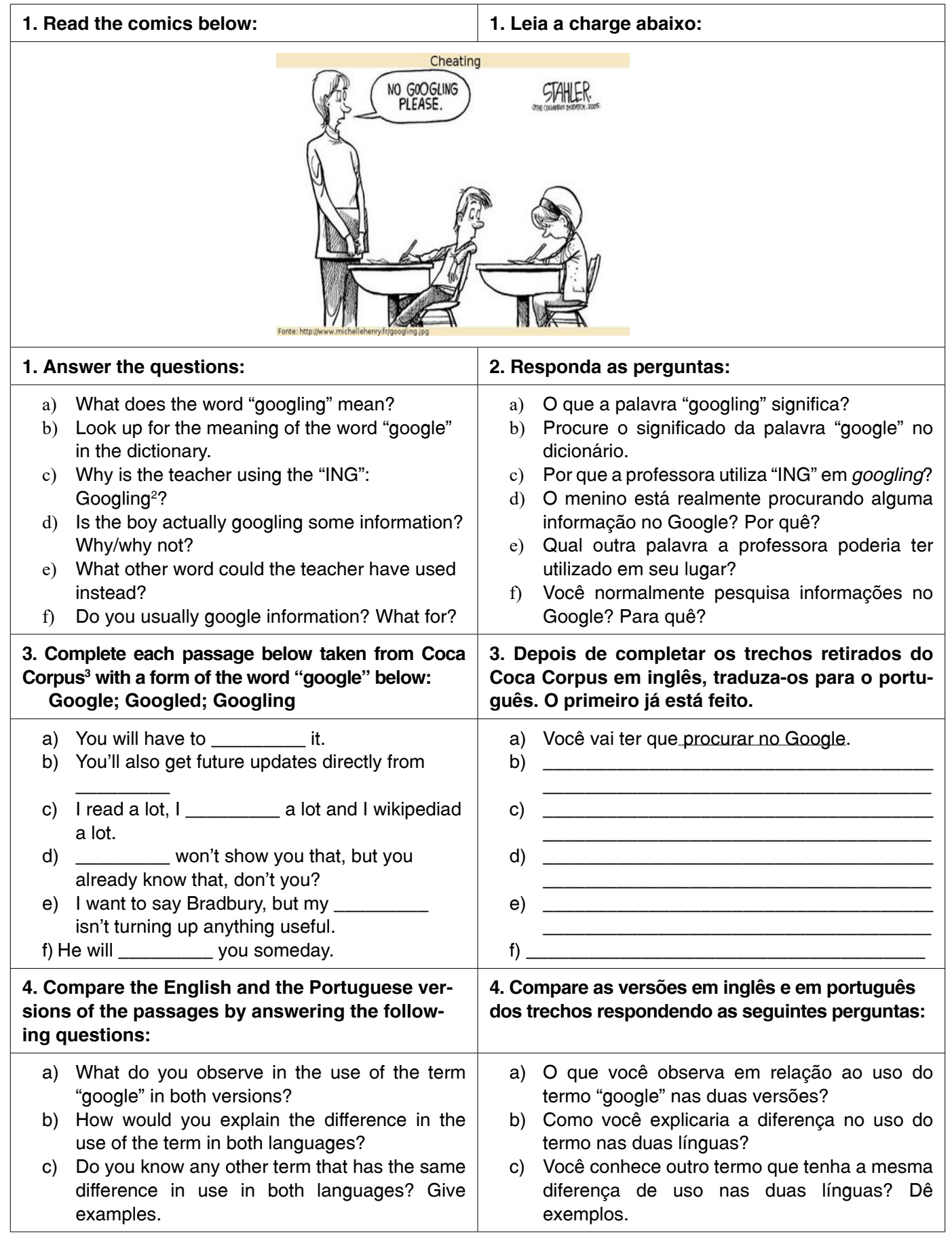

Fonte: elaboração dos autores. 
Quadro 7 - Tarefa VI: Same words, different pronunciation!

1. Read Flora Lewis' quote. What is your opinion about it? If necessary, look up for the words in the dictionary.
1. Leia a citação de Flora Lewis. Qual a sua opinião? Se necessário procure as palavras no dicionário.

\section{Learning another language is not only learning different words for the same things, but learning another way to think about things. \\ Flora Lewis}

\section{Gather in groups and do the following:}

1. Record your voices pronouncing the sentence "Learning another language is ".

2. Check the possible pronunciations among the group.

3. Observe the words pronounced in "different Englishes" Using the interactive map.
2. Reúnam-se em grupos e façam o seguinte:

1. Gravem as suas vozes pronunciando a frase "Learning another language is ___.".

2. Verifiquem as possíveis pronúncias entre o grupo.

3. Observem as palavras pronunciadas em "diferentes ingleses" usando o mapa interativo.

Fonte: elaboração dos autores.

Quadro 8 - Tarefa VII: Brazilian people speaking

\begin{tabular}{|c|c|}
\hline $\begin{array}{l}\text { 1. Watch the video " } 24 \mathrm{H} \text { falando somente em } \\
\text { inglês com brasileiros" (2.15-5.45 min) and an- } \\
\text { swer the questions below. } \\
\text { https://www.youtube.com/watch?v=GfyxYJBDjko }\end{array}$ & $\begin{array}{l}\text { 1. Assista o vídeo " } 24 \mathrm{H} \text { falando somente em in- } \\
\text { glês com brasileiros" ( } 2.15-5.45 \mathrm{~min}) \text { e respon- } \\
\text { da as perguntas abaixo. } \\
\text { https://www.youtube.com/watch?v=GfyxYJBDjko }\end{array}$ \\
\hline $\begin{array}{l}\text { a) What do you think about the Brazilians' perfor- } \\
\text { mances? }\end{array}$ & $\begin{array}{l}\text { a) O que você acha do desempenho dos brasi- } \\
\text { leiros? }\end{array}$ \\
\hline b) Do they have different accents? & b) Eles têm diferentes sotaques? \\
\hline c) Did they communicate their message? & c) Eles/as comunicaram suas mensagens? \\
\hline $\begin{array}{l}\text { d) Why did the girl speak two languages at the same } \\
\text { time? Was her performance enough to effectively } \\
\text { communicate with the man? Why/Why not? }\end{array}$ & $\begin{array}{l}\text { d) Por que a garota falou duas línguas ao mesmo } \\
\text { tempo? O desempenho dela foi suficiente para } \\
\text { se comunicar como o homem? Por quê? }\end{array}$ \\
\hline $\begin{array}{l}\text { e) How would you feel if you had a conversation in } \\
\text { English with someone? }\end{array}$ & $\begin{array}{l}\text { e) Como você se sentiria se tivesse uma conver- } \\
\text { sa em inglês como alguém? }\end{array}$ \\
\hline
\end{tabular}

Fonte: elaboração dos autores. 
Quadro 9 - Tarefa VIII: We all have different accents Portuguese

This is your final task for the trimester, and we are going to record ourselves. In order to do that you must:

In pairs or trios, choose two comic strips provided by the teacher (one in English and another in Portuguese) and act it out. You're going to rehearse and after that, present to the group and record a video.

Before you start your presentation, introduce yourself: tell your name and where you are from.

At the end, we'll produce the video together, joining all presentations.

As English is a global language, we might show the world that Brazilians learn and speak English, too.
Esta é sua tarefa final para o trimestre e nós vamos gravar um vídeo. Para isso vocês devem:

Em duplas ou em trios, escolha duas tirinhas fornecidas pela professora (uma em inglês e a outra em português) e interpretem cada uma. Vocês vão ensaiar e depois disso, apresentar para o grupo e gravar um vídeo.

Antes de começar a apresentação, lembrem-se de falar seus nomes e de onde vocês são.

No final, iremos produzir um vídeo juntos compilando todas as apresentações.

Como o inglês é uma língua global, nós podemos mostrar para o mundo que brasileiros aprendem e falam inglês também.

Fonte: elaboração dos autores.

\section{Conclusões}

Considera-se que o ensino de língua adicional, no contexto da educação popular, em uma perspectiva de aprendizado com base em tarefas e de gêneros discursivos, está alinhado à aprendizagem colaborativa através da prática. Dessa forma, partindo de textos autênticos que circulam entre falantes da língua inglesa e do conceito de inglês como língua global, esta proposta teve o intuito de promover a reflexão sobre as diversas manifestações da língua entre seus usuários pelo mundo.
Sua produção foi pautada na construção de uma UD sobre variação linguística para o ensino de língua adicional, em um contexto de educação popular, em que a aprendizagem ocorre de maneira situada e colaborativa. Como resultado, espera-se que, ao final da UD, os alunos compreendam a dinamicidade e a diversidade que envolvem o idioma e, aprendendo juntos, tenham seus repertórios expandidos e enriquecidos pelo uso e pela expressão de sua primeira língua e de suas línguas adicionais, podendo, assim, continuar seus estudos sobre a língua por meio de temas variados, ao longo do curso. 


\section{World Englishes: a didactic unit designed for young adults from a vulnerable community}

\section{Abstract}

This article presents a proposal for a didactic unit designed for young mid-lower class and lower-class adults, who live in a vulnerable community located in Porto Alegre. The didactic unit is part of a dissertation project, that aims at developing a course addressed to the needs and interests of the community members. The proposal is framed on studies about collaborative learning, popular education, language variation, discourse genres, and task-based learning. The main objective of the proposal is to recognize the possible different variations among speakers of the same language. In language teaching, it is considered fundamental to raise awareness about language manifestations that are different from the standard, as well as to understand the cultural aspects involving linguistic phenomena. Grounded on the students' realities, the discussion on the variations in the English language is proposed starting from the same phenomenon in the Portuguese language.

Keywords: Collaborative learning. English language. Popular education.

\section{Notas}

1 Essa escolha se justifica contemporaneamente por diversas razões, a começar pela ênfase no acréscimo que a disciplina traz a quem se ocupa dela, em adição a outras línguas que o educando já tenha em seu repertório, particularmente a língua portuguesa. Em diversas comunidades de nosso estado, essa língua adicional não é a segunda, pois outras línguas estão presentes, como é o caso das comunidades surdas, indígenas, de imigrantes e de descendentes de imigrantes. (SCHLATTER; GARCEZ, 2012, p. 127).

2 Pressupõe-se que os alunos já estão familiarizados com o uso do gerúndio no presente contínuo na língua inglesa.

3 https://www.english-corpora.org/coca/.

\section{Referências}

BAKHTIN, Mikael. Estética da criação verbal. Tradução de Maria Ermantina Galvão. 5. ed. São Paulo: Martins Fontes, 2010.

BRASIL. Base Nacional Comum Curricular (BNCC). Educação é a Base. Brasília, DF: MEC/CONSED/UNDIME, 2018. Disponível em: http://basenacionalcomum.mec.gov.br/a-base. Acesso em: 26 jul. 2020.

CLARK, H. H. O uso da linguagem. Cadernos de Tradução, Porto Alegre: UFRGS, n. 9, p. 49-71, jan./mar. 2000.

CRYSTAL, David. English as a Global Language. 2. ed. Cambridge: Cambridge University Press, 2009.

GADOTTI, Moacir. Educação popular, educação social, educação comunitária: conceitos e práticas diversas, cimentadas por uma causa comum. Revista Dialogos, Brasília, v. 18, n. 1, dez. 2012.

MEDEIROS, L. M.; FONTOURA, H. A. da. O desafio de ensinar língua inglesa na Educação de Jovens e Adultos. Revista de Educação Popular, v. 16, n. 1, p. 82-91, 2 jun. 2017.

MANGABEIRA, Andréa B. A. Participação, identidade e variação na EJA: o uso variável da concordância nominal de número com recurso simbólico e estilístico na construção de uma comunidade de prática na sala de aula de língua portuguesa. Dissertação (Mestrado em Educação) - UFRGS, Porto Alegre, 2012.

SCHLATTER, M.; GARCEZ, P. de M. Línguas adicionais na escola: aprendizagens colaborativas em inglês. Erechim: Edelbra, 2012. 
VAN DEN BRANDEN, K. Task-based language teaching. In: HALL, G. (ed.). The Routledge Handbook of English Language Teaching. London: Routledge, 2016. p. 238251.

WELP, Anamaria. Novas perspectivas para a sala de aula de língua adicional. In: CONGRESSO BRASILEIRO DE LINGUÍSTICA APLICADA, 9, 2011, Rio de Janeiro. Anais [...]. Rio de Janeiro: ALAB, 2011. p. 1-12. 